\title{
Hospitalidade linguística e tradução: digressões acerca da tarefa do tradutor
}

\author{
Augusto Leite, UFMG
}

Resumo: O presente artigo busca contribuir para a discussão do texto "A tarefa do tradutor" de Walter Benjamin, a partir da leitura do filósofo francês Paul Ricœur do texto de Benjamin em questão. Pretende-se desenvolver, ainda, as implicações teóricas das propostas contidas no texto sobre a tarefa do tradutor, particularmente a ideia de língua pura - reine Sprache.

Palavras-chave: Benjamin; tradução; língua pura.

Aus beiden Sprachen baut er etwas auf und kann gemeinhin schon von Glück sagen, wenn sein Gerüst ein wenig länger als ein Kartenhaus sich hält. (BENJAMIN, 1991, vol. III, p. 40; grifo nosso)

[A partir de ambas as línguas ele está construindo algo; e pode dizer ainda sobre felicidade se sua espinha dorsal sustém algo mais que um castelo de cartas.]

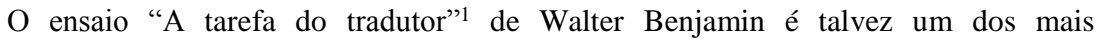
comentados textos de sua juventude. Nele, assertivas sobre o caráter messiânico da língua pura, ou língua da verdade, expressam com grande intensidade o teor teológico de sua teoria da linguagem. Esse caráter messiânico é comumente entendido como aquele que expressa uma afinidade meta-histórica das línguas e assegura a realização integral dessa afinidade em uma língua futura, que redimiria as línguas naturais de suas falibilidades. Existiria uma intimidade entre as línguas anunciadora da língua pura que, antes da confusão entre as línguas que se averigua, era a língua que guardava a verdade, injustiçada pelas decadentes línguas naturais contemporâneas. Porém, seria possível compreender de outra maneira esse caráter messiânico da teoria benjaminiana: não enquanto promessa, porvir, mas enquanto realização no presente.

Sobre essa fraternidade linguística e a promessa que nela contém, o filósofo Paul Ricœur dedica três pequenos ensaios na compilação Sobre a Tradução. Em "Desafio e Felicidade na Tradução", "O Paradigma da Tradução" e "Uma 'Passagem': traduzir o intraduzível”, Ricœur realiza uma crítica à teoria messiânico-linguística de Benjamin que, de alguma forma, poderia ser uma releitura da mesma.

Em "Desafio e Felicidade na Tradução", Ricœur diz, tomando emprestadas suas próprias palavras, das grandes dificuldades e das pequenas felicidades da tradução. Tradução que, assim como na acepção da tarefa - Aufgabe - benjaminiana, pode ser um trabalho - Arbeit - de luto, ou de lembrança, em suas acepções freudianas: luto do original traduzido, e lembrança da perda inerente à tarefa, que também é, justamente, renúncia. A ideia de tradução de Ricœur assume um caráter semelhante à e distante da ideia de tradução de Benjamin no labor de luto do original a partir da recepção de sua tradução. Para compreensão disso, passa-se aqui à apresentação da ideia de tradução ricœuriana. 
A partir da reflexão sobre o ensaio "Cultura e tradução na Alemanha romântica", de Antoine Berman, Ricœur, inicialmente, problematiza a figura do "estrangeiro". Segundo o filósofo francês, "dois parceiros são de fato colocados em relação pelo ato de traduzir, o estrangeiro [...] e o leitor"2; entre esses dois, averiguasse o tradutor. O estrangeiro seria a figura original, aquele que é levado até a presença do leitor, então, pelo trabalho do tradutor. Para tanto, esse tradutor, o meio entre esses dois, realiza um trabalho, uma tarefa-renúncia, na qual tanto autor vai até o leitor, quanto leitor vai até o autor. Como na máxima de Friedrich Schleiermacher, lembrada por Ricœur, que diz: "levar o leitor ao autor", "levar o autor ao leitor": o original e o traduzido se encontram nesse terceiro plano, o plano da tradução. Nele, no encontro, ocorreria, segundo o raciocínio ricœuriano, uma resistência à consciência da perda, tanto da tradução em relação ao original, quanto do original em relação à tradução.

Um fantasma de uma tradução perfeita, nas palavras de Ricœur, juntamente com os lapsos de intraduzibilidade, engendraram um drama trágico no qual aqueles espíritos totalizantes, tais como Goethe, Schiller, Novalis, são os personagens que estariam em busca de uma poética da tradução universal, absoluta. Os textos de filosofia e, especialmente, os de poesia eram alvo de teorias e mais teorias sobre a tradução, justamente por eles, os textos poéticos e filosóficos, comportarem todos os elementos da linguagem: a sonoridade, o significado, o significante e uma semântica rigorosa. Porém, esses espíritos totalizantes não chegam a nenhuma ideia além daquelas em que apenas a tradução perfeita interessa. Ricœur não se interessa pela tradução perfeita. A proposta de Ricœur passa pela aceitação de que no ato de tradução a perda é incontornável; assim, não há tradução perfeita. A tradução comporta, ela mesma, o seu maior defeito: não ser o original; e isso não é devido a inexorável perda inerente a ela. Mas, por outro lado, é precisamente nessa perda em que, paradoxalmente, ganha-se a consciência da tarefarenúncia do tradutor. Seria preciso, segundo Ricœur, fazer o luto desse ganho sem perda, desse sonho da tradução perfeita onde não há diferença entre original e tradução. O luto, ou processo de consciência da perda, seria um processo-chave para o alcance da felicidade na tradução. "É esse luto da tradução absoluta que faz a felicidade de traduzir." 3

Ricœur credita à teoria benjaminiana da língua pura essa vontade de alcance de uma tradução sem perda; o que, como já dito, é tarefa impossível. O filósofo francês acredita que uma consciência de perda e seu respectivo luto daria à relação entre o próprio e o estrangeiro o ganho da convivência, da coexistência. A proposta final de Ricœur, em seus contornos últimos políticos, seria a de uma convivência na diferença. ${ }^{4}$ Dessa forma, pode-se traduzir

sem esperança de eliminar a distância entre equivalência e adequação total. Hospitalidade linguística portanto, onde o prazer de habitar a língua do outro é compensado pelo prazer de receber em casa , a acolhida de sua própria morada, a palavra do estrangeiro. ${ }^{5}$

A crítica de Ricœur, assim, dirige-se diretamente ao caráter messiânico da filosofia da linguagem de Walter Benjamin. Nela, o exegeta francês encontra ecos de um romantismo, cuja busca pelo absoluto, em suas palavras, não obteve nada senão a intolerância diante da perda. Essa postura intolerante diante da perda que, por um lado, sobrevaloriza o original, pode tanto insuflar o amor pelo estrangeiro - pelo outro, pelo original estrangeiro - quanto desvalorizá-lo; a ponto de, em último caso, não aceitar sua 
existência. À tradução perpassa a questão da relação entre o próprio e o outro e, em seu estudo, Ricœur está atento a isso.

Em "O Paradigma da Tradução", o autor se dedica ao comentário de uma passagem bíblica que, tal como a passagem do Gênesis sobre a criação do homem e sua atualidade divino-criativa tratada por Benjamin no texto sobre a linguagem em geral e a linguagem do homem, sintetiza um problema que, antes de ser próprio à literatura judeo-cristã, seria próprio à humanidade. $\mathrm{O}$ texto de que se fala é a passagem sobre Babel: a construção da torre que iria ao encontro de Deus nos céus e, por conseguinte, a confusão que assolou a terra após o próprio Deus destituir a humanidade de sua língua única, confundindo as línguas e lábios dos homens. Cita-se:

Ora, toda a terra tinha uma só língua e um só idioma. ${ }^{6}$ E deslocando-se os homens para o oriente, acharam um vale na terra de Sinar; e ali habitaram. Disseram uns aos outros: Eia pois, façamos tijolos, e queimemo-los bem. Os tijolos lhes serviram de pedras e o betume de argamassa. Disseram mais: Eia, edifiquemos para nós uma cidade e uma torre cujo cume toque no céu, e façamo-nos um nome, para que não sejamos espalhados sobre a face de toda a terra. Então desceu o Senhor para ver a cidade e a torre que os filhos dos homens edificavam; e disse: Eis que o povo é um e todos têm uma só língua; e isto é o que começam a fazer; agora não haverá restrição para tudo o que eles intentarem fazer. Eia, desçamos, e confundamos ali a sua linguagem, para que não entenda um a língua do outro. Assim o Senhor os espalhou dali sobre a face de toda a terra; e cessaram de edificar a cidade. Por isso se chamou o seu nome $\mathrm{Babel}^{7}$, porquanto ali confundiu o Senhor a linguagem de toda a terra, e dali o Senhor os espalhou sobre a face de toda a terra. ${ }^{8}$

Essa narrativa falaria de uma humanidade que, ao buscar o conhecimento das coisas divinas, confunde-se pela ação da própria divindade. Literal e imediatamente, a passagem trata da existência de uma língua única e o surgimento de línguas diversas após a ação de Deus sobre os homens. A narrativa babélica faria mais sonhar do que propriamente conduziria a alguma solução sobre a questão da dificuldade comunicativa entre as línguas, segundo Ricœur. Diferente da corriqueira interpretação da pequena estória, onde se vê na dispersão-confusão uma catástrofe irremediável, o que Ricœur enxerga nessa narrativa é o chamado do homem em forma de parábola: o chamado à tradução.

A narrativa babélica sintetizaria, para Ricœur, a tarefa a que a humanidade fora chamada, a tradução. Tradução aqui se encerra no sentido mais amplo de "compreensão". O livro de George Steiner, Após Babel, citado algumas vezes por Ricœur, sempre se presta a enfatizar o fato de que traduzir é inerente à vida humana; que traduzir seria o mesmo que conscientizar-se ou compreender. Ricœur não lê Babel enquanto mito de condenação da humanidade à eterna incompreensão e estado bélico, mas, sim, como constatação de uma separação original, sem condenação. Um mito que aponta para a tomada de consciência do caráter diverso e idiossincrático de cada sujeito, cada língua, cada experiência.

Sobre a experiência, Ricœur não fala propriamente. Porém, ao relacionar os pequenos ensaios aqui apreciados com outra obra do autor, a trilogia Tempo e Narrativa, uma percepção dessa experiência pode ter lugar. A experiência seria o mediador entre original e tradução. $\mathrm{O}$ tradutor só traduz porque compartilha uma experiência comum ao original e à tradução. $O$ tradutor seria aquele quem compreende as experiências que se entrecruzam e que, numa linguagem ricœuriana, podem ser configuradas numa narrativa 
tal que compreenda tanto o teor de experiência do original quanto o teor de experiência da tradução, articulando-as em signos, regras, normas, mediatizáveis e coapresentáveis.

Para o filósofo francês, traduzir é um projeto ético. A fraternidade entre as línguas que se anuncia no ato da tradução seria mais um esforço dos poliglotas de configurar uma experiência limiar chamada tradução, do que um dado a priori, um destino suspenso, a espera de se realizar. E a ética da tradução residiria, especialmente, na conscientização da impossibilidade da tradução perfeita; seu luto e a consequente convivência $n a$ diferença. Nesse sentido, apesar de a ideia de uma tradução perfeita, propriamente dita, ser impossível, o ato de traduzir guarda essa potencialidade, a de se realizar, mesmo de forma falha, e, por outro lado, a de não se realizar plenamente, indicando o caminho da hospitalidade linguística como saída para a questão. Assim, de alguma maneira, a ideia benjaminiana messiânica de redenção presente na tradução ainda persiste em Ricœur.

As intraduzibilidades são o sinal da possibilidade da tradução e, também, de seus limites. Os limites da linguagem em geral. A tradução se realizaria nos pequenos momentos de felicidade, como diz Ricœur. E, essa felicidade, bonheur, é mesmo a "boa hora", 9 a hora certa, o momento chave quando a traduzibilidade do texto se encontra com sua cognoscibilidade no presente. Apenas nesse breve momento, é que a tradução se realiza; fugidia, incompleta, imprecisa, dependente da experiência do original e dela mesma enquanto tradução. O que se espera, então, é sua consciência.

\section{Uma solução messiânica para Babel: hospedar o estrangeiro}

A partir dessa crítica ricœuriana à teoria da tradução de Walter Benjamin, que suscita várias questões, uma, particularmente, se impõe ao trabalho que aqui se realiza, qual seja: traduzir ou conviver na diferença?

Conviver na diferença parece uma saída ideal, visto que as intraduzibilidades, as falibilidades, as incomunicabilidades, são tantas! Ora, conviver na diferença priva o sujeito de passar pelos desconfortos próprios à tradução que, como averiguado, são incontornáveis. Conviver na diferença exercitaria a tolerância, virtude diplomática. Conviver na diferença e a consequente tolerância que dela se pode derivar reservam um grande apelo humanístico. Mas como conviver com o outro sem o compreender? Sem a tradução, a compreensão entre diferentes é impossível. E é a tradução que guarda, ela mesma, a chave para a convivência na diferença, em uma virtude que Ricœur nomeou de hospitalidade linguística. Traduzir, assim, é, em si, conviver na diferença, quando consciente de seus limites. E, em outras palavras, condição ontológica do conviver na diferença: $o$ ato de traduzir.

Em um mundo babélico, a tradução seria a chave para a compreensão mútua. Visto que a comunicação intralinguística já reserva seu teor de incomunicabilidade e a comunicação entre línguas anuncia perigos maiores, como os elencados anteriormente, a tradução enquanto compreensão é o exercício que solucionaria, dentro de suas possibilidades, essa tensão: a tensão entre o próprio e o estrangeiro. A tradução, assim, insere-se nessa tensão como solução. Ela remarca a afinidade entre as línguas, lembrando que sua possibilidade é a prova disso. "A tradução torna presente sobre um modo somente antecipador, anunciador, quase profético, uma afinidade que não está jamais presente", ${ }^{10}$ diz Jacques Derrida em seu ensaio "Torres de Babel". A tradução, pois, acalma a tensão entre as línguas e seu desentendimento próprio pelo anuncio de suas afinidades.

A leitura que Derrida realiza do ensaio sobre a "Tarefa do tradutor" é atenta a uma característica obscura, esotérica, de uma proposição benjaminiana pouco visada, a saber, 
a do caráter limiar, intangível da língua pura, ou da verdade, que é produto do ato de traduzir. A língua da verdade se porta como enigma, intangível; porém, é somente por sua existência que a tradução se torna possível. Ela não é materialmente exprimível ou mesmo poder-se-ia dizer de alguma lógica própria a ela. Não contém uma gramática, tal como a língua mística divina de Abraão Abuláfia, uma língua que a referência à realidade é amálgama da letra ou palavra que nem mesmo a representa, mas é ela mesma. Aproxima-se da ideia de ideografia - Begriffsschrift - de Gottlob Frege, língua que se basta por dar a todos os objetos e tropos nomes próprios inconfundíveis.

Se traduzir é uma tarefa possível, visto que poliglotas existem (sem que necessariamente eles sejam esquizofrênicos, como sublinha Ricœur), a língua pura seria aquela que liga uma língua a outra, que fornece às duas seu conteúdo comum; ela é limiar - Schwelle -, transição, fluxo. ${ }^{11}$ Para se apreender tal língua, a tarefa-renúncia deve ser a de trabalhar a palavra, sua sintaxe, até o nível semântico dos sentidos dos enunciados, chama a atenção, Benjamin, ele mesmo, no texto sobe a tarefa do tradutor. Ora, ao se traduzir uma obra do grego para o português, seria preciso apreender as afinidades entre as duas línguas e, por conseguinte, tornar o português o mais grego possível. É um trabalho que exige o luto daquele intraduzível e a doação da forma original à tradução, que, por fim, faz perviver, sobreviver, o original em sua cognoscibilidade na tradução. Aquilo que o grego emprestou ao português nessa possível tradução é, justamente, fragmento da língua pura, ou da verdade; fragmento das afinidades entre essas duas línguas; sinal da intimidade que elas têm. Aí, precisamente, reside a língua pura em seu caráter propriamente monadológico, apreensível como fragmento, apenas; mas um fragmento que diz de sua forma total. Vale, no entanto, atentar para o limite aqui anunciado, a saber, o da tradução em par. A tradução, para Benjamin, só seria possível em duplas, ou seja, não mais que duas línguas devem estar envolvidas.

A tarefa do tradutor, confinada no duelo das línguas (nunca mais de duas línguas), dá lugar somente ao "esforço criador" (esforço e tendência mais que acabamento, labor artesanal mais que performance de artista), e quando o tradutor "cria", é como um pintor que "copia" seu "modelo" ...'] $]^{12}$

A criação tradutora exige que apenas duas línguas sejam as envolvidas, pois, precisamente de uma língua para a outra a letra, a palavra e a sentença do original se recria, se refigura para, então, $n a$ tradução, tornar-se inteligível. A tradução da tradução seria possível, mas, não comportaria mais o conteúdo de verdade do original, e, sim, o conteúdo de verdade da tradução do original. A tradução da tradução não revelaria mais nenhuma intimidade com o original; ela é gasta, vazia daquele conteúdo de verdade do original, segundo Benjamin. Nela já não é mais a experiência contida no original a que se anuncia, mas a da tradução do original que, como visto, tem o grande defeito de simplesmente não ser o original e, dessa forma, comportar outra experiência: a da tradução.

Em relação à traduzibilidade intralinguística, a palavra guarda sua precariedade. A palavra que oprime o sentido na própria língua não cessa de o oprimir até que seja liberta da necessidade de dar sentido a algo. Portanto, é apenas na língua pura, no intercurso da tradução que ela cessa seu trabalho opressor, livrando-se do fardo de se referir a algo. A liberdade que a língua pura reserva é também índice de sua presença na tradução, livre por excelência. A língua pura, portanto, é limiar que se apreende nos fragmentos de conteúdo de verdade anunciados em cada tradução. "O limiar é uma zona [...] às vezes não estritamente definida - como deve ser definida a fronteira -; ele lembra fluxos e 
contrafluxos, viagens e desejos", ${ }^{13}$ explica Jeanne-Marie Gagnebin. O conceito de limiar que expressa, em suma, uma transição, um copertencimento, é expressão da tradução. $\mathrm{O}$ limiar, então, caracteriza-se por se inserir em um intervalo entre o antes e o depois, o antes da língua original e o depois da tradução; esse hiato que, nele, exercita a compreensão própria à tarefa-renúncia do tradutor.

A língua pura, ou da verdade, copertenceria, a partir do entendimento de seu caráter limiar, a todas as línguas. E nelas, ela está. Nelas, a língua pura se estende em fragmentos apresentáveis na e pela tradução. Nessa tradução, que seria nada mais que o trabalho de hospedar o estrangeiro, hospedagem linguística, realizar-se-ia a consciência desse copertencimento, uma pertença recíproca - Zusammengehörigkeit ${ }^{14}$ - que nada mais é que compreensão. Partindo da ideia de que a língua pura benjaminiana não pressupõe uma fraternidade universal a priori entre as línguas, mas anuncia sua criação, artificialmente, pela via da tradução, essa, sim, possibilidade e propriedade a priori das línguas, poder-se-ia ter na tradução, nela mesma, a própria realização de um ideal messiânico; ideal no qual o teor fraternal das línguas não seria uma mera promessa, no âmbito da crença, mas realidade.

\begin{abstract}
This paper aims to contribute to the discussion of Walter Benjamin's text "The Task of the Translator" through the reading of the french philosopher Paul Ricœur. It is intended to develop also the theoretical implications of the proposals contained in the text on the translator's task, particularly the idea of pure language - reine Sprache.
\end{abstract}

Keywords: Benjamin; Translation; Pure language.

\title{
Referências bibliográficas
}

BENJAMIN, Walter; TIEDEMANN, Rolf; SCHWEPPENHÄUSER, Hermann. Gesammelte Schriften. Frankfurt am Main: Suhrkamp, 1991. 7 v.

BENJAMIN, Walter. Origem do drama trágico alemão. Trad. João Barrento. Belo Horizonte: Autêntica, 2011.

BENJAMIN, Walter; TIEDEMANN, Rolf; BOLLE, Willi; MATOS, Olgaria C. F.; ARON, Irene. Passagens. Belo Horizonte: Editora UFMG; São Paulo: Imprensa Oficial do Estado de São Paulo, 2006.

BENJAMIN, Walter. Escritos sobre mito e linguagem: (1915-1921). São Paulo: Duas Cidades: Ed. 34, 2011.

BENJAMIN, Walter. The correspondence of Walter Benjamin, 1910-1940. Chicago: University of Chicago Press, c1994.

DERRIDA, Jacques. Torres de Babel. Belo Horizonte: Editora UFMG, 2002. 
GAGNEBIN, Jeanne-Marie. História e narração em W. Benjamin. Campinas, SP: São Paulo: Perspectiva / FAPESP / UNICAMP, 1994.

GAGNEBIN, Jeanne-Marie. Sete aulas sobre linguagem, memoria e historia. Rio de Janeiro: Imago, 1997.

LEVY, Gabriel. Prophecy, Written Language, and the Mimetic Faculty: Benjamin's Linguistic Mysticism as Cure of the 'Language Myth'. Epoché: The University of California Journal for the Study of Religion, v. 24, p. 19-48, 2006.

LÖWY, Michael; BRANT, Wanda Nogueira Caldeira.; GAGNEBIN, Jeanne-Marie; MULLER, Marcos Lutz. Walter Benjamin: aviso de incêndio: uma leitura das teses 'Sobre o conceito de história'. São Paulo: Boitempo, 2005.

MACHADO, Francisco de Ambrosis Pinheiro. Imanência e história: a crítica do conhecimento em Walter Benjamin. Belo Horizonte: Editora UFMG, 2004.

MOSÈS, Stéphane. L'Ange de l'Histoire. Éditions Gallimard, 2006.

OTTE, Georg; SEDLMAYER-PINTO, Sabrina; CORNELSEN, Elcio Loureiro. Limiares e passagens em Walter Benjamin. Belo Horizonte: Editora UFMG, 2010.

REIS, José Carlos. História da 'consciência histórica' ocidental contemporânea: Hegel, Nietzsche, Ricœur. Belo Horizonte: Autêntica, 2011.

RICOEUR, Paul; LAVELLE, Patrícia. Sobre a tradução. Belo Horizonte: Editora UFMG, 2011.

SCHOLEM, Gershom. O Nome de Deus, a teoria da linguagem e outros estudos de cabala e mística. Judaica II. Ed. Perspectiva: São Paulo, 1999. p. 31-36.

WITTE, Bernd e CAMPOS, Haroldo de. O que é mais importante: a escrita ou o escrito? Teoria da linguagem em Walter Benjamin. In: Walter Benjamin. Trad. de Bernd Witte por Georg Bernard Sperper. São Paulo: Revista da USP, n. 15, 1992.

WOHLFARTH, Irvign. On Some Jewish Motifs in Benjamin. In: BENJAMIN, A. (Org.) The Problems of Modernity: Adorno and Benjamin, p. 157-215. London: Routledge, 1989.

\section{Notas}

1 "Die Aufgabe des Übersetzers". In: BENJAMIN, Walter; TIEDEMANN, Rolf; SCHWEPPENHÄUSER, Hermann. Gesammelte Schriften. Vol. IV, 1. p 9-21. Tradução escolhida em: BENJAMIN, Walter. Escritos sobre mito e linguagem: (1915-1921). São Paulo: Duas Cidades: Ed. 34, 2011.

${ }^{2}$ RICEEUR. Sobre a tradução. p22.

${ }^{3}$ RICEUR. Sobre a tradução. p29. 
${ }^{4} \mathrm{O}$ professor José Carlos Reis, em sua obra História da 'Consciência Histórica' Ocidental Contemporânea, na qual discute Hegel, Nietzsche e Ricœur, e seus respectivos projetos de história, lembra os contornos políticos da proposta ricœuriana que "se posiciona entre a 'reconciliação total', oferecida pela consciência absoluta de Hegel, e a 'ruptura total', proposta pela força-plástica/esquecimento de Nietzsche". Nessa obra citada, o historiador avalia Ricœur como conciliador. Ver: REIS, José Carlos. História da 'consciência histórica' ocidental contemporânea: Hegel, Nietzsche, Ricœur. Belo Horizonte: Autêntica, 2011. p. 318.

${ }^{5}$ RICEEUR. Sobre a tradução. p. 30.

${ }^{6}$ Sa'adiah Gaon, estudioso judeo-babilônico medieval, explica que essa mesma língua poderia significar um mesmo ideal, uma mesma ideologia; ou, simplesmente, um mesmo discurso.

${ }^{7}$ Derivação de balal que significa misturar até tornar confuso. Essa confusão é tal que não se pode perceber que essa confusão se passou, pois a origem já se tornou inapreensível.

${ }^{8}$ Gênesis 11: 1 - 9. Tanakh traduzido da versão hebraica do Mekhon Mamre. Tradução: João Ferreira de Almeida da União Sefardita Hispano-Portuguesa (Israel) com notas do Rabino J. de Oliveira. Ver: http://www.judaismo-iberico.org/interlinear/tanakh/ 0111PT.HTM.

9 Jogo com o vocábulo francês bonheur, realizado por Patrícia Lavelle no prefácio a tradução portuguesa dos textos de Ricoeur, Sobre a Tradução. Ali, ela, partindo o vocábulo, traduz parte por parte: bon-heur: boa-hora.

${ }^{10}$ DERRIDA. Torres de Babel.p. 44.

${ }^{11}$ BENJAMIN. Passagens. p. 535 (Fragmento O 2a, 1).

12 DERRIDA. Torres de Babel. p. 62.

13 OTTE, Georg; SEDLMAYER-PINTO, Sabrina; CORNELSEN, Elcio Loureiro. Limiares e passagens em Walter Benjamin. Belo Horizonte: Editora UFMG, 2010. p. 14.

14 Vocábulo utilizado por Benjamin no "Prefácio epistemo-crítico" para dizer da relação intima entre verdade, fenômeno e conceito, na alegoria da constelação e das estrelas já anteriormente desenvolvida. Ver: BENJAMIN, Walter; TIEDEMANN, Rolf; SCHWEPPENHAUSER, Hermann. Gesammelte Schriften. I,1. p. 215. 